\title{
A high performance system to study the influence of temperature in on-line solid-phase extraction capillary electrophoresis
}

\author{
Marcos Tascon ${ }^{a}$, Fernando Benavente ${ }^{c}$, Victoria Sanz-Nebot ${ }^{c}$, Leonardo G. Gagliardi ${ }^{\mathrm{a}, \mathrm{b}, *}$ \\ a Laboratorio de Investigación y Desarrollo de Métodos Analíticos (LIDMA), Universidad Nacional de La Plata, Calle 47 y 115 (1900), La Plata. Buenos Aires, \\ Argentina \\ ${ }^{\mathrm{b}}$ Centro de Investigación y Desarrollo en Tecnología de Pinturas (CIDEPINT-CIC-CONICET), Av. 52 y 120 (1900), La Plata, Buenos Aires, Argentina \\ c Departamento de Química Analítica, Universidad de Barcelona, Av. Diagonal 645, Barcelona, España
}

H I G H L I G H T S

- A new system to switch temperature of microcartridges in on-line SPE-CE is presented.

- The system allows switching the SPE temperature from $5{ }^{\circ} \mathrm{C}$ to $90^{\circ} \mathrm{C}$ in about $30 \mathrm{~s}$.

- A systematic study of temperature of opioid peptides in C18-SPE-CE analysis is shown.

- Best $\mathrm{S} / \mathrm{N}$ ratios are obtained for load, elution and $\mathrm{CE}$ separations at $60^{\circ} \mathrm{C}$, $25^{\circ} \mathrm{C}$ and $25^{\circ} \mathrm{C}$.

- Improvements are demonstrated for both, standard and spiked plasma samples.

\section{A R T I C L E I N F O}

\section{Article history:}

Received 22 August 2014

Received in revised form 24 December 2014

Accepted 27 December 2014

Available online 31 December 2014

\section{Keywords:}

Capillary electrophoresis

On-line pre-concentration

Opioid peptides

Solid-Phase extraction

Temperature

(1)

G R A P H I C A L A B S T R A C T
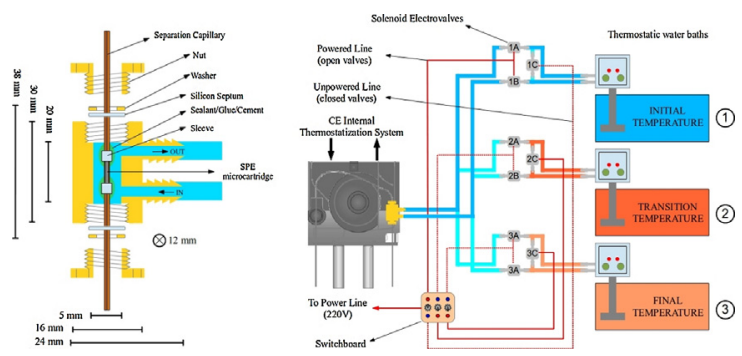

\begin{abstract}
A B S T R A C T
A novel high performance system to control the temperature of the microcartridge in on-line solid phase extraction capillary electrophoresis (SPE-CE) is introduced. The mini-device consists in a thermostatic bath that fits inside of the cassette of any commercial CE instrument, while its temperature is controlled from an external circuit of liquid connecting three different water baths. The circuits are controlled from a switchboard connected to an array of electrovalves that allow to rapidly alternate the water circulation through the mini-thermostatic-bath between temperatures from 5 to $90^{\circ} \mathrm{C}$. The combination of the minidevice and the forced-air thermostatization system of the commercial CE instrument allows to optimize independently the temperature of the sample loading, the clean-up, the analyte elution and the electrophoretic separation steps.

The system is used to study the effect of temperature on the C18-SPE-CE analysis of the opioid peptides, Dynorphin A (Dyn A), Endomorphin1 (END) and Met-enkephalin (MET), in both standard solutions and in spiked plasma samples. Extraction recoveries demonstrated to depend, with a nonmonotonous trend, on the microcartridge temperature during the sample loading and became maximum at $60^{\circ} \mathrm{C}$. Results prove the potential of temperature control to further enhance sensitivity in SPE-CE when analytes are thermally stable.
\end{abstract}

() 2015 Elsevier B.V. All rights reserved.

\footnotetext{
* Corresponding author. Fax: +54 2214226947.

E-mail address: leogagliardi@quimica.unlp.edu.ar (L.G. Gagliardi).
} 


\section{Introduction}

Capillary electrophoresis (CE) is the technique which provides the highest efficiencies in liquid phase separations. However, as any other micro- or nano-technique, the poor limit of detection (LOD) is a challenging issue. Different approaches have been described in order to overcome this drawback. Some of them imply the use of different detection systems [1,2], while others are based on the use of analyte preconcentration procedures [3-6]. Both strategies are useful and, since they are relatively independent from each other, they can be used simultaneously [7].

Within the different preconcentration approaches, one of the most interesting is on-line solid phase extraction capillary electrophoresis (SPE-CE) [8,9]. In SPE-CE, an extraction microcartridge, which contains a solid phase sorbent to retain the target analyte from a large volume of sample, is inserted near the inlet of the separation capillary. After rinsing to eliminate non-retained compounds, the retained analyte is eluted in a small volume of an appropriate solution, resulting in sample clean-up and concentration enhancement with minimum sample handling. The extraordinary capability of SPE-CE to improve LODs has been extensively proved for analytes of different chemical nature - i.e., peptides, pesticides, etc. $[6,10,11]$, in different sample matrices (biological fluids, tissues, environmental samples, etc.) by using a wide variety of sorbents ( $\mathrm{C} 18, \mathrm{C} 8$, polymeric, molecular imprinted polymers, antibodies, etc.). Moreover, this methodology has been employed with different type of detectors such as ultraviolet (UV), light induced fluorescence (LIF) and mass spectrometry (MS) [7,8]. In SPE-CE, the need of improved preconcentration factors and higher analysis throughputs make temperature a variable of interest, and the miniaturized dimensions facilitate temperature control and handling.

One of the most noticeable effects of temperature in separation techniques involving fluid dynamics, such as LC and CE, is the change of viscosity. It is well known that in LC backpressure can be reduced at high temperatures due to the decrease on the mobile phase viscosity, and several home-made thermostatization systems have been reported to work with columns of reduced particle size [12]. Temperature has additional effects: as it is increased the analysis time is reduced, the diffusion coefficients also increase and mass transfer kinetics are improved, the chromatographic efficiencies are better, etc. [13]. In some cases, a change of temperature may promote simultaneous effects, on retention and ionization equilibrium [14], on retention and conformation [15], or other [16]. These studies, together with the pioneer works in LC [17], provide a sound basis on fluid dynamics, thermodynamics and chemical equilibriums, useful to understand the influence of temperature in SPE. Despite chemical nature of SPE sorbents are essentially the same to that used as stationary phases in LC; some relevant differences can be found in practice. In LC the system operates under the so called elution mode, where the analytes are at infinite dilution [18], whereas SPE constitutes a frontal analysis. In this case the sorbent is fed continuously with a sample constituting the mobile phase of the system. Therefore, analyte retention occurs under conditions sometimes far from the infinite dilution and changes on the loading temperature could have different and not easily predictable effects on extraction efficiencies. Likewise, it would be noteworthy to evaluate other steps of the SPE process, such as sample matrix clean-up or analyte elution. However, there are just a few works dealing with the influence of temperature on SPE and most of them are related with gas chromatography (GC) environmental analysis - i.e., purge and trap methods. Despite the potential of using temperature as an optimization variable in SPE-CE has been mentioned [19], to the best of our knowledge, there are no reports on thermostatic setups specifically designed for SPE-CE.
In similar extent than in LC, on CE the temperature has also important effects. Different research groups have been focused on explaining the radial temperature profiles and the loss of efficiency promoted by the Joule heating effect [20]. In contrast, only a few have demonstrated that temperature can be used to improve the $\mathrm{CE}$ separation [21,22]. Commercial CE instruments are usually equipped with an internal thermostatization system to prevent the undesired Joule heating effects. In general, a peltier element controls the temperature of a thermostatic fluid, - air or liquid - circulating around the capillary tube coiled in a cartridge cassette. This internal system does not provide high versatility to handle the temperature (e.g., fast gradients, wide ranges, extreme values, etc.), but it allows to perform some basic studies about the influence of temperature on CE [22] and, as we will show in this paper, also on SPE-CE.

The goal of this study is to systematically explore for the first time the influence of temperature in SPE-CE using, in a first approach, the internal forced-air thermostatization system of the commercial instrument and, later, a specifically designed minithermostatic device (MTD) which allows to control and rapidly switch the temperature of the microcartridge. A typical C18 is used as sorbent in the SPE microcartridges, and several opioid peptides related to analgesia and pain modulation are used as model analytes. Changes in sample and background electrolyte (BGE) viscosity, migration times, retention, etc. are investigated in detail to establish a general instrumental and methodological framework to exploit the potential of temperature in SPE-CE and other similar approaches involving the on-line coupling to $C E$ of similar microcartridges (chemical or enzymatic reactors, filtration membranes, etc.).

\section{Experimental}

\subsection{Materials and reagents}

Acetonitrile, methanol, 2-propanol, formic acid (HFo, 98-100\%), acetic acid (HAc, glacial), ammonia (25\%) and sodium hydroxide were from Merck (Darmstadt, Germany). Deionized water was provided by a MilliQ system (Millipore, Molsheim, France). All chemicals used in the preparation of buffers and solutions were of analytical grade or better. Methionine-enkephalin (MET, aminoacid sequence: Tyr-Gly-Gly-Phe-Met 573.23 Da) and endomorphin 1 (END, aminoacid sequence: Tyr-Pro-Trp- Phe-NH2, 610.29 Da) were provided by Sigma (St. Louis, MO, USA). Dynorphin A (1-7) (Dyn A, aminoacid sequence: Tyr-Gly-Gly-Phe-Leu-Arg-Arg 867.47 Da) was supplied by Bachem (Bubendorf, Switzerland). Cellulose acetate filters of $10 \mathrm{kDa}$ molecular weight cut-off (MWCO) (Amicon ${ }^{\circledR}$ Ultra-0.5 centrifugal devices) were provided by Millipore (Bedford, MA, USA). Fused silica capillaries for CE and SPE-CE were supplied by Polymicro Technologies Inc. (Phoenix, AZ, USA). For the manufacturing of the microcartridges several plastic tubing were investigated as sleeves: Tygon ${ }^{\circledR}(0.25 \mathrm{~mm}$ id, ColeParmer, Vernon Hills, USA), polyethylene $(0.25 \mathrm{~mm}$ id, ColeParmer, Vernon Hills, USA) and silicon ( $0.3 \mathrm{~mm}$ id, Colmic, Reggello, FI, Italy and $0.2 \mathrm{~mm}$ id, Stonfo, Campi Bisenzio, FI, Italy). Several glues, sealants and cements were also tested: Fastix ${ }^{\circledR}$ (Akapol S.A., Buenos Aires, Argentina), Artic Silver ${ }^{\circledR}$ (Artic Silver, Visalia, CA, USA), Nural $25^{\circledR}$ (Pattex, Barcelona, Spain) and Araldit ${ }^{\circledR}$ alta temperatura (Ceys, L'Hospitalet de Llobregat, BCN, Spain). The C18 sorbent (particle size $50-105 \mu \mathrm{m}$ ) and the material for the frits of the microcartridges were obtained from 1 cc SPE Sep-Pack cartridges (Waters, Milford, MA, USA).

\subsection{Instrumental}

All experiments were performed on an Agilent Technologies HPCE3D system with a DAD detector (Waldbronn, Germany). $\mathrm{pH}$ 
measurements were performed with a Crison 2002 potentiometer and a Crison electrode 5203 (Crison Instruments, Barcelona, Spain). Centrifugation and ultrafiltration procedures were carried out in a centrifuge 5417R (Eppendorf Ibérica, Madrid, Spain). Two thermostatic baths Lauda T and one cryostat MGW Lauda K4R (Lauda, Lauda-Königshofen, Germany) ( $\mathrm{T}$ precision was in all cases $\pm 0.1^{\circ} \mathrm{C}$ ), nine common (washing-machine) solenoid electrovalves compatible with hot water and an electric switchboard were used for the home-made thermostatization set-up. Additionally the temperature was measured with a standard thermocouple.

\subsection{Procedures}

\subsubsection{Construction of temperature resistant microcartridges for SPE-} CE

The construction of the SPE microcartridge or analyte concentrator was done as described in a previous report [8]. A $57 \mathrm{~cm} \mathrm{LT} \times 75 \mu \mathrm{m}$ id $\times 365 \mu \mathrm{m}$ od fused-silica capillary was prepared and activated by flushing for $20 \mathrm{~min}$ with aqueous $1 \mathrm{M} \mathrm{NaOH}$, followed by $15 \mathrm{~min}$ with water and $30 \mathrm{~min}$ with the separation electrolyte. It was cut in two pieces, of 9.0 and $48.0 \mathrm{~cm}$, in order to insert the microcartridge between them. The process of fabrication was monitored under a stereomicroscope. A polyethylene frit $(0.1 \mathrm{~cm})$, obtained from a small fragment of the original filters found in C18 Sep-Pak cartridges (Waters, Milford, MA, USA), was introduced in the body of the microcartridge, i.e., a small piece of bare fused-silica capillary $(7 \mathrm{~mm}$ $\mathrm{LT} \times 250 \mu \mathrm{m}$ id $\times 365 \mu \mathrm{m}$ od). The body of the microcartridge was coupled to the $7.5 \mathrm{~cm}$ piece of capillary using a $0.5 \mathrm{~cm}$ Tygon ${ }^{\circledR}$ sleeve ( $280 \mu \mathrm{m}$ id $610 \mu \mathrm{m}$ od). Thus, it was easily vacuum-filled with $\mathrm{C} 18$ sorbent from the Sep-Pak Cartridge. When the tube was almost completely full, a second polyethylene frit $(0.1 \mathrm{~cm})$ was inserted in the end side. The column was extended to full length with the $64.5-\mathrm{cm}$ piece of capillary using another Tygon sleeve. The use of Tygon ${ }^{\mathbb{R}}$ tube as a connection sleeve covered with a thin layer of Araldit ${ }^{\circledR}$ epoxy glue was the best combination of materials providing mechanical support, physical sealing and electric insulation.

The SPE-CE columns were conditioned by flushing at $930 \mathrm{mbar}$ with water $(10 \mathrm{~min})$, methanol $(5 \mathrm{~min})$, water $(5 \mathrm{~min})$ and BGE (5 min). Finally, 10 min of running voltage were applied. It must be pointed out that stationary phase used in this work is stable within a $\mathrm{pH}$ range between 2 and 8 and then, it results in limitations: on one hand, no $\mathrm{NaOH}$ can be used in pre/post conditionings and, on the other, an optimization of the BGE conditions for the subsequent $\mathrm{CE}$ separation is restricted to this $\mathrm{pH}$ range. Pre-conditionings of the SPE-CE system consisted of flushing at the rinsing pressure of the instrument the following solutions: water $(1 \mathrm{~min})$, methanol $(1 \mathrm{~min})$, water $(1 \mathrm{~min})$. The sample was, then, introduced hydrodynamically by applying $930 \mathrm{mbar}$ for $10 \mathrm{~min}$. Finally BGE was flushed $2 \mathrm{~min}$ as a light clean-up step and to fill the separation capillary with the running electrolyte. Afterward, an elution plug consisting of $50 \mathrm{mM}$ acetic acid and $50 \mathrm{mM}$ formic acid solution prepared in methanol:water 60:40 by volume was injected (e.g., for $25^{\circ} \mathrm{C}$ carried out applying 50 mbar for $10 \mathrm{~s}$ ) followed by separation at $25 \mathrm{kV}$. After each run and as a postconditioning step, capillaries were flushed with acetonitrile ( $2 \mathrm{~min}$ ) and water ( $2 \mathrm{~min}$ ) in order to reestablish the initial conditions of the microcartridge.
A

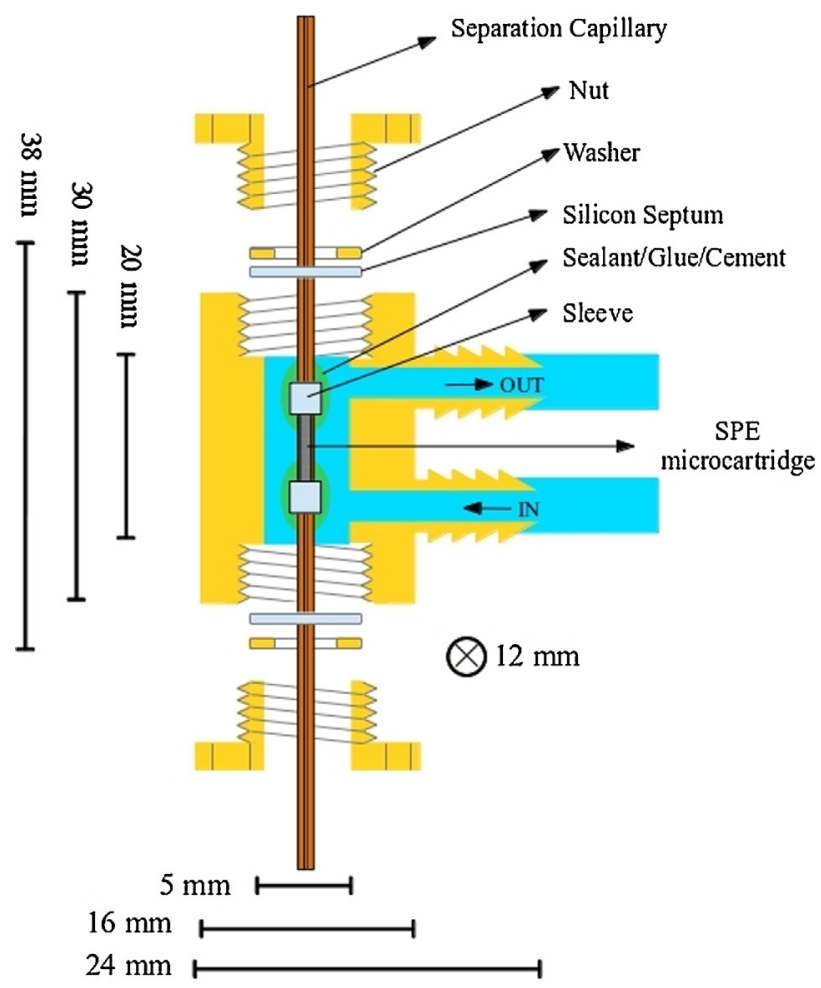

B
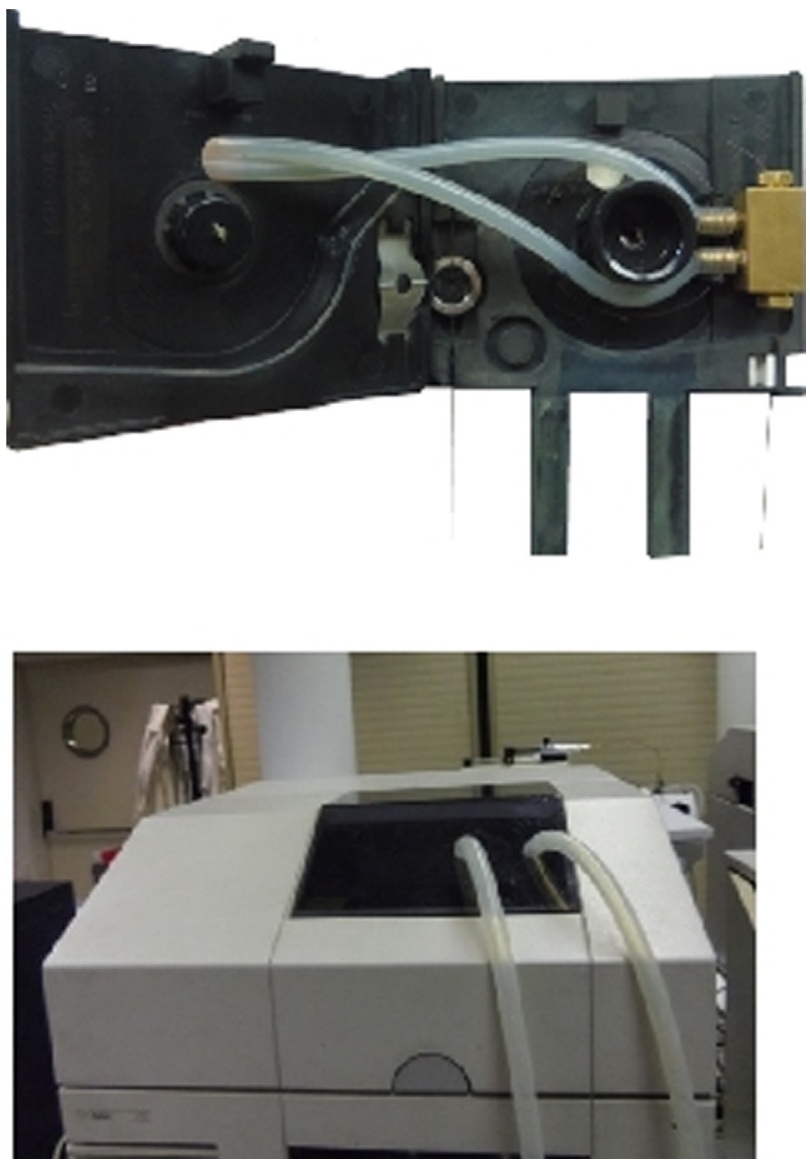

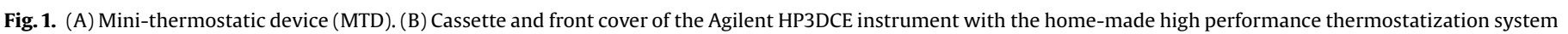
installed on it. 


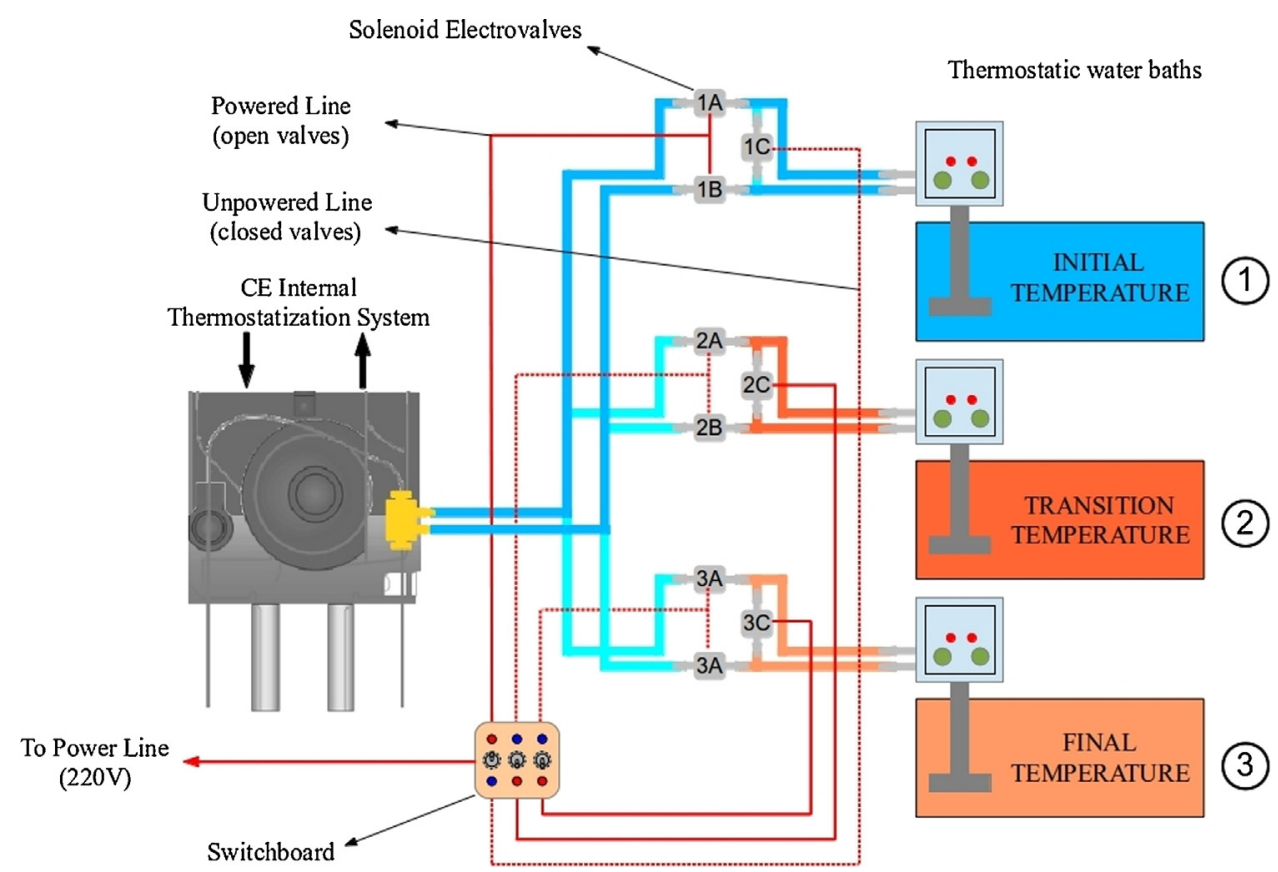

Fig. 2. Diagram of the electric circuit connected to the solenoid electrovalves of the external water bath circuit to control the MTD temperature.

\subsubsection{Temperature in SPE-CE with the internal thermostatization system}

Firstly, the whole SPE-CE procedure - i.e., sample loading, clean-up, elution and separation - was carried out at different temperatures from $25^{\circ} \mathrm{C}$ to $60^{\circ} \mathrm{C}$. The electrophoretic conditions, mobilities, migration order and other results reported by SanzNebot et al. [23] for these same analytes were used as a reference. Secondly, the entire process was divided in two steps: on the first step the sample loadings and clean-up, were done at certain temperature and, on the second step, elution and the separations were done at other temperatures. Temperature was automatically changed and a lag time was considered between steps to stabilize the last temperature. As was described in a previous section all the clean-ups of the SPE-CE sequences carried out in this work consisted of a simple sample matrix elimination by gently rinsing with BGE, but the use of stronger solvents may be also admitted. Different combinations of extreme temperatures within the range allowed by the instrument were evaluated for both steps (low-high and vice versa). In order to avoid differences in the loaded volumes due to the change of viscosity with temperature, the loading times were corrected based on the change of the water viscosity and the Hagen-Poiseuille equation [24].

Temperature stability of peptides was demonstrated by analyzing a $10 \mu \mathrm{g} \mathrm{mL}^{-1}$ standard mixtures before and after being at $95^{\circ} \mathrm{C}$ during $1 \mathrm{~h}$ in a water bath.

\subsubsection{Design of the home-made high performance thermostatization system}

The system consisted of a mini-thermostatic device (MTD) that allowed a localized thermostatic bath on the extraction microcartridge, which fits inside of the cassette of any commercial CE instrument, and an external circuit of thermostatting liquid involving three different water baths, nine electrovalves and an electric switchboard to rapidly change the temperature of the liquid delivered to the microcartridge. Fig. 1A represents the MTD. It was made by machining a flat and rectangular piece of metal (30 mm length $\times 16 \mathrm{~mm}$ width $\times 12 \mathrm{~mm}$ height). Considering a variety of properties, such as the ease of machining, the mechanical and the corrosion resistance or the thermal conductivity, the preferred material was bronze (135g). A $5 \mathrm{~mm}$ width and $20 \mathrm{~mm}$ long cylindrical channel drilled along the main length formed the chamber where the microcartridge was encased. The extremes were closed with two silicon rubber flat disk septa, which were pierced with the open capillary inlet and outlet. The septa were compressed by washers and bored nuts, tightening the capillary, fixing the microcartridge position and avoiding leaks of thermostatting liquid inside the $\mathrm{CE}$ instrument.

On the extremes of the MTD chamber, two side channels communicate with external ports to the thermostatization circuit. The length of these tubes was minimum and they were covered with insulating foam in order to reduce the loss of heat. The MTD was tested and fitted into the cassette of different commercial CE instruments. Fig. 1B shows the MTD in the Agilent Technologies CE cassette and the modified instrument cover to accommodate the silicon tubes.

The external circuit of water was integrated by three thermostatic baths connected to the ports of the MTD. Fig. 2 illustrates the arrangement of water baths, electrovalves and the electric circuit. The electric circuit of each water bath (1,2 or 3 ) was controlled with a group of three electrovalves (A, B or C). A three point alternating switch allowed to open simultaneously the valves $A$ and $B$ (powered line indicated with a continuous line in Fig. 2) while valve $C$ (unpowered line, dotted line in Fig. 2) remained closed or vice versa. Fig. 2 shows the condition where the temperature of the MTD was controlled by water bath 1 (valves $1 \mathrm{~A}$ and $1 \mathrm{~B}$ were open and $1 \mathrm{C}$ closed) and the water baths 2 and 3 were in recirculation (valves $2 \mathrm{C}$ and $3 \mathrm{C}$ were open and the rest closed). In our experiments, water baths 1 and 3 were controlling the initial and final temperature of the microcartridge, respectively, while temperature of water bath 2 (transition bath) was appropriately selected to speed-up the change of temperature. Once the MTD arrived to the end temperature, the circuit was rapidly switched to the water bath 3 to stabilize the final temperature.

The water flow rates measured at $25^{\circ} \mathrm{C}$ were $2.81 \mathrm{~min}^{-1}$ for the two Lauda T water baths, and $3.91 \mathrm{~min}^{-1}$ in the case of the MGW Lauda K4R cryostatic bath. When experiments required the use of temperatures below room temperature the priority of use of the cryostatic bath was to control the temperature at the lower value. 
Otherwise, and considering its higher flow rates of this bath, it was connected as transition bath in order to accelerate the heat transfer in the MTD and the change of temperature.

As an example, to switch the temperature from $5^{\circ} \mathrm{C}$ to $90^{\circ} \mathrm{C}$ cryostat was connected as initial bath, 1 , the Lauda $\mathrm{T}$ bath providing higher flow rates set at the maximum temperature $\left(98^{\circ} \mathrm{C}\right)$ was connected as transition bath, 2 , while the last Lauda $\mathrm{T}$ regulated at $94^{\circ} \mathrm{C}$ was connected as final temperature water bath, 3 , to control the temperature of the MTD at $90^{\circ} \mathrm{C}$. In this conditions the change of temperature from $5{ }^{\circ} \mathrm{C}$ to $90^{\circ} \mathrm{C}$ required around $30 \mathrm{~s}$ (a calibrated thermocouple was set inside the microcartridge chamber for these temperature measurements). Since the thermostatic liquid used in this work was water, and considering that stability and mechanical resistance of the materials used to construct the extraction microcartridges had been tested only up to $95^{\circ} \mathrm{C}$, the maximum temperature used in the MTD was $90^{\circ} \mathrm{C}$.

\subsubsection{Temperature in SPE-CE with the high-performance thermostatization system}

In the SPE-CE experiments, the temperature of the separation capillary was permanently set at $25^{\circ} \mathrm{C}$ with the internal thermostatization system, while the temperature of the microcartridge was controlled by the home-made MTD. The SPE-CE analysis was again divided in two steps. The first step of sample loading and clean-up was investigated at different temperatures between $5^{\circ} \mathrm{C}$ and $90^{\circ} \mathrm{C}$. Then, the temperature of the MTD was rapidly switched to $25^{\circ} \mathrm{C}$, for the second step of elution and separation.

Since the change of temperature was focused on the extraction microcartridge, which is responsible of a significant part of the total backpressure, in these SPE-CE experiments a different strategy was used to correct the injection and loading times. The sample loading flow rates at the different temperatures have been determined eluting by pressure a small plug of methanol as a hold-up marker ( $3 \mathrm{~s}$ at $30 \mathrm{mbar}$ for $25^{\circ} \mathrm{C}$ ). The ratio between the hold-up time at a certain temperature and the hold-up time obtained at $25^{\circ} \mathrm{C}$, called hydrodynamic correction factor (f), was used to correct sample loading time required at that temperature to introduce the same sample volume loaded in the reference experiment performed at $25^{\circ} \mathrm{C}$.

\subsubsection{Sample pretreatment}

A pool of human blood plasma from healthy blood donors was kindly supplied by the Banc de Sang i Teixits (Hospital de la Vall d'Hebron, Barcelona, Spain). The samples were spiked with the three peptides at a level concentration of $100 \mathrm{ng} \mathrm{mL}^{-1}$ of each one. The spiked plasma samples were treated off-line before SPE-CE analyses to prevent microcartridge saturation. A double step pretreatment that consisted of precipitation with acetonitrile (acetonitrile:plasma 6:1 v/v) followed by centrifugal filtration was applied. Peptide recoveries were optimum after a passivation of the centrifugal filters with polyethylene glycol (PEG) (23\%,69\% and 86\% for Dyn A, END and MET, respectively) [9].

\section{Results and discussions}

\subsection{Internal thermostatization system to study the temperature in SPE-CE}

The internal thermostatization system of the commercial instrument was used to study the effect of using different temperatures on the complete SPE-CE analyses of a $10 \mathrm{ng} \mathrm{mL}^{-1}$ standard mixture of the three opioid peptides. It can be expected that improvements of $\mathrm{S} / \mathrm{N}$ ratio would be produced mainly by the increment of the signal more than for the reduction of noise. Then, two hypotheses can be considered: (1) to improve the retention in the loading step or (2) to improve the elution to start the CE separation from a more concentrated and compressed band.

The use of a clean-up temperature different than the loading temperature will undoubtedly not increase the quantity of retained analyte and it could be even on the contrary: part of the retained analytes could be lost. Therefore, loading and clean-up must be at the same temperature.

Elution can be done either at the load + clean-up temperature, or either at the separation temperature. In order to elucidate this effects, firstly, different analyses were performed by thermostatting the whole SPE-CE set at different temperatures between $25^{\circ} \mathrm{C}$ and $60^{\circ} \mathrm{C}$. The results obtained at three of the studied temperatures are shown in the plots of Fig. 3 with their corresponding blank sample analyses below. In the labels of the plots a notation is introduced in which the cassette temperatures set at the loading + clean-up step, and at the elution + separation step are indicated by hyphenated numbers. In these first experiments the same temperature was used on both steps. It must be pointed out the loss of separation efficiency is a regular issue when a microcartridge is located on-line with the separation [8,25,26], a specific comparison of this peptides analyzed by CE and SPE-CE using C18 was found in a work performed by Hernández et al. [26].

As expected, the most noticeable effect of temperature was the reduction of analysis time (e.g., a change of temperature from 25$25^{\circ} \mathrm{C}$ to $60-60^{\circ} \mathrm{C}$ reduced the time of analysis from almost $30 \mathrm{~min}$ to almost $10 \mathrm{~min}$.).

Regarding the $\mathrm{S} / \mathrm{N}$, it must be pointed out that it can indicate potentials to improve or deteriorate the LOD in further validations on real samples. Since a UV detector was used in all the experiments of this work, the peak widths and, consequently, the peak areas are dependent on the analyte velocities. Therefore, peak areas used to calculate $\mathrm{S} / \mathrm{N}$ ratios must be corrected dividing by migration time [27].

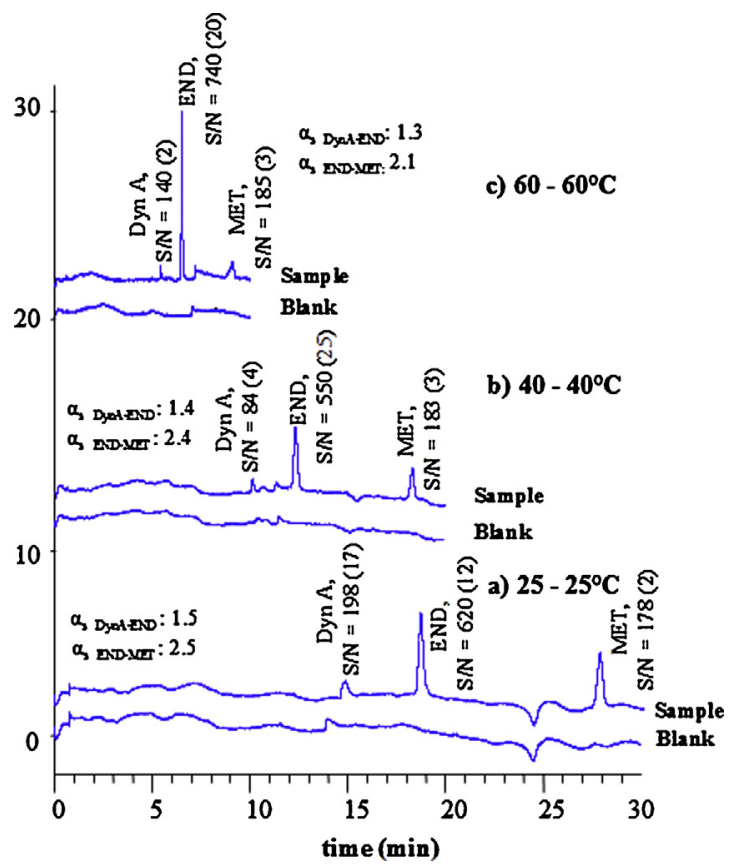

Fig. 3. Analysis of a standard mixture of Dyn A, END and MET at $10 \mathrm{ng} \mathrm{mL}^{-1}$ by SPE$\mathrm{CE}$ using the internal thermostatization system. (a) Loading/clean-up at $25^{\circ} \mathrm{C}$ and elution/separation at $25^{\circ} \mathrm{C}$, (b) Loading/clean-up at $40^{\circ} \mathrm{C}$ and elution/separation at $40^{\circ} \mathrm{C}$ and, (c) Loading/clean-up at $60^{\circ} \mathrm{C}$ and elution/separation at $60^{\circ} \mathrm{C}$. S/N have been corrected by migration velocities and the corresponding s.d. between replicates are shown in parentheses. Other separation conditions: BGE $50 \mathrm{mM}$ HFo and $50 \mathrm{mM} \mathrm{HAc} 50 \mathrm{mM}$ ( $\mathrm{pH} 3.5$ ) and $25 \mathrm{kV}$. The sample loading volumes for SPE-CEUV were $85 \mu \mathrm{L}$ at all temperatures. 


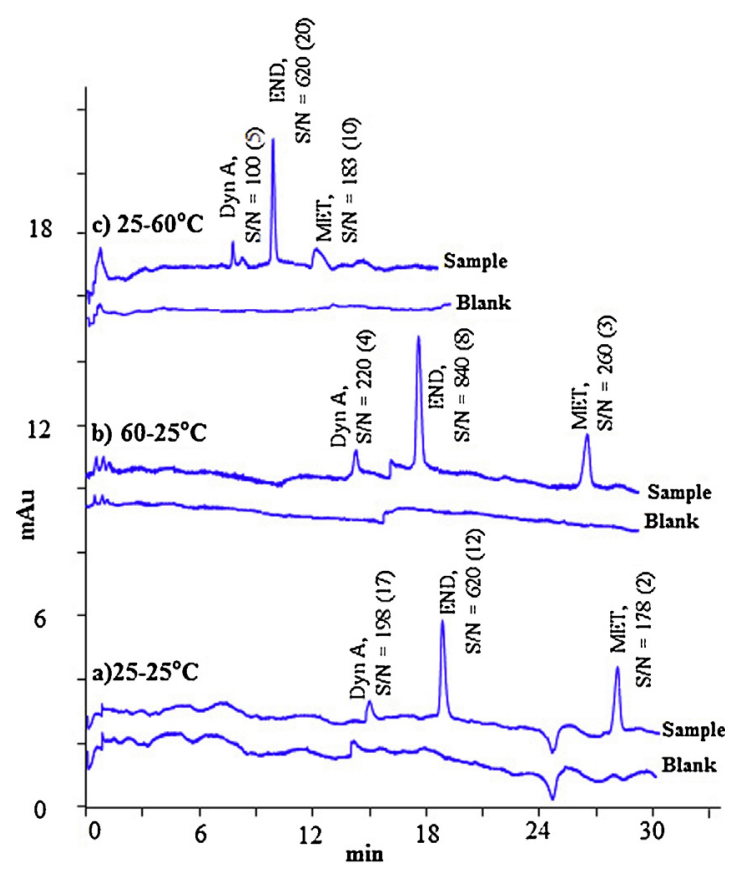

Fig. 4. Analysis of a standard mixture of Dyn A, END and MET at $10 \mathrm{ng} \mathrm{mL}^{-1}$ by SPECE. (a) Loading/clean-up $25^{\circ} \mathrm{C}$ and elution/separation at $25^{\circ} \mathrm{C}$, (b) loading/clean-up at $60^{\circ} \mathrm{C}$ and elution/separation at $25^{\circ} \mathrm{C}$ and (c) loading and clean-up at $25^{\circ} \mathrm{C}$ and elution/separation at $60^{\circ} \mathrm{C}$. S/N have been corrected by migration velocities and the corresponding s.d. between replicates are shown in parentheses. Other separation conditions: BGE $50 \mathrm{mM}$ HFo and $50 \mathrm{mM}$ HAc $50 \mathrm{mM}$ (pH 3.5) and $25 \mathrm{kV}$. The sample loading volumes were of $85 \mu \mathrm{L}$ all conditions.

When temperature is raised from the initial $25^{\circ} \mathrm{C}$, in the case of END, the first increment of temperature produces a reduction in the $\mathrm{S} / \mathrm{N}$ ratio of about $11 \%$ and then an increment of $35 \%$. In agreement with the aforementioned behavior, for Dyn A the first increment of temperature produces a reduction in the $\mathrm{S} / \mathrm{N}$ ratio of $58 \%$ and, then an increment $67 \%$. In both cases the $\mathrm{S} / \mathrm{N}$ becomes minimum at the intermediate temperatures of the studied range. In the case of MET, the $\mathrm{S} / \mathrm{N}$ ratios do not show significant variations and do not elucidate a clear trend. It can be assumed that in this case the variation of cassette temperature do not change the $S / N$.

These results suggest a possible combination of temperature effects, some of them improving the $\mathrm{S} / \mathrm{N}$ ratios and some other becoming them worse. In this case, these effects could be produced on different steps of the SPE-CE procedure. Therefore in order to elucidate this, new experiments were done but using different temperatures in the different parts of the SPE-CE procedure.

Based on the same notation criterion used previously, results of these new experiments are shown in Fig. 4. In Plot (a) the results of 25-25 shown previously in Fig. 3 was included in order to use it as a reference. Plot (b) show the results obtained when high temperature is used only in the first part (loading and cleanup), and Plot (c) when high temperature is used only in the second part (elution and separation).

Comparison of the $\mathrm{S} / \mathrm{N}$ ratios in experiment $25-25^{\circ} \mathrm{C}$ vs $60-25^{\circ} \mathrm{C}$ demonstrate that the use of higher temperatures in the first part (sample loading and clean-up) produce clear improvements in the $\mathrm{S} / \mathrm{N}$ ratios for the three studied analytes.

The comparison of experiments $25-25^{\circ} \mathrm{C}$ vs $25-60^{\circ} \mathrm{C}$ show that, for Dyn $A$ the $S / N$ ratios can be strongly deteriorated, while for END and MET the change of temperature of the second part (elution and separation) do not affect significantly the $\mathrm{S} / \mathrm{N}$ ratios. These results reaffirm the idea of having simultaneous effects when the temperature of the complete system SPE-CE is increased: an improvement of the $\mathrm{S} / \mathrm{N}$ in the first part with the SPE microcartridge at higher temperature, and a detriment when the CE separation is achieved also at higher temperatures.

Since temperature is effectively improving the SPE-CE procedure in the loading step we went forward with a systematic study of the temperature effect on the sample loading. However, the internal thermostatting system presented several drawbacks that made us to search for an alternative system to explore temperature influence on SPE-CE: the available temperature range was quite short, temperature changes were slow and heat transfer not much efficient for rapid temperature gradients. For example, using the internal system in the experiment called $25-60^{\circ} \mathrm{C}$, the heating step between the loading/clean-up at $25^{\circ} \mathrm{C}$ and the elution/separation at $60^{\circ} \mathrm{C}$ was taking about $10 \mathrm{~min}$, as well as $20 \mathrm{~min}$ the change of temperature in the experiment $60-25^{\circ} \mathrm{C}$.

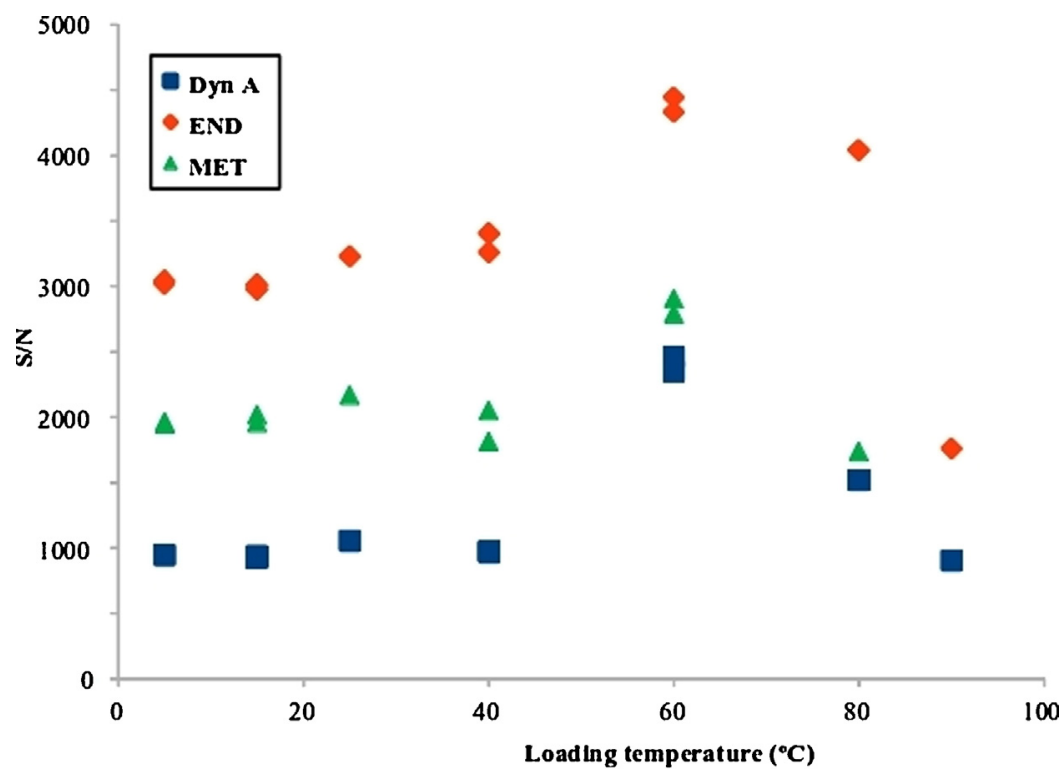

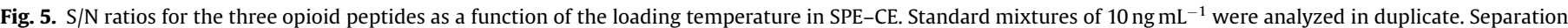

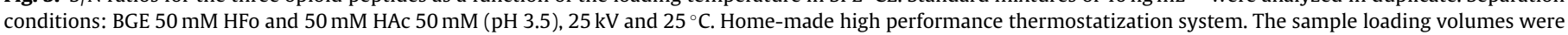
$85 \mu \mathrm{L}$ in all cases. 

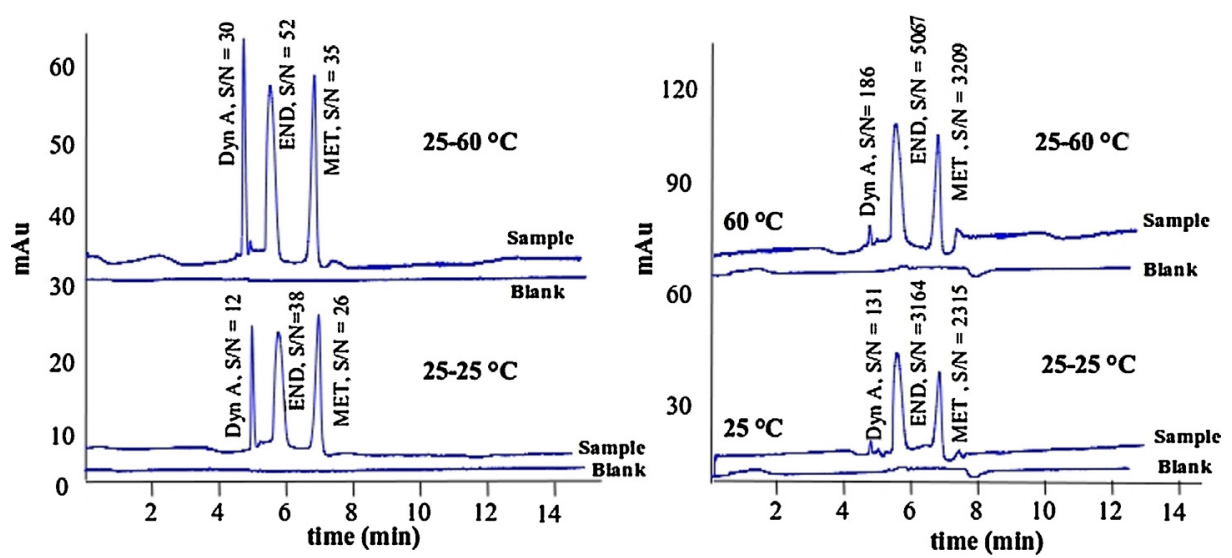

Fig. 6. Analysis by SPE-CE at different loading temperatures of (A) a standard mixture of the opioid peptides at $10 \mathrm{ng} \mathrm{mL}^{-1}$ and (B) plasma sample spiked with the opioid peptides at $100 \mathrm{ng} \mathrm{mL}^{-1}$.A double step pretreatment based on precipitation with acetonitrile followed by centrifugal filtration was applied to plasma samples). Separation conditions: BGE $50 \mathrm{mM}$ HFo and $50 \mathrm{mM} \mathrm{HAc} 50 \mathrm{mM}$ (pH 3.5), $25 \mathrm{kV}$ and $25^{\circ} \mathrm{C}$. Home-made high performance thermostatization system. The loaded volumes were $85 \mu \mathrm{L}$ at all the temperatures, for standard and plasma samples.

\subsection{Home-made high performance thermostatization system to optimize the temperature in SPE-CE}

The home-made high performance MTD was used to study the sample loading/clean-up temperature within the range between $5^{\circ} \mathrm{C}$ and $90^{\circ} \mathrm{C}$, while the elution/separation step was subsequently carried out with the internal thermostatization system at $25^{\circ} \mathrm{C}$. The MTD allowed to have an independent control of the temperature in a restricted zone for the SPE microcartridge, provided a wider temperature range (i.e., at least from $5^{\circ} \mathrm{C}$ to $90^{\circ} \mathrm{C}$ when using water as thermostatting liquid), as well as rapid temperature gradients for a high efficiency switching between temperatures.

Fig. 5 shows a plot of the $\mathrm{S} / \mathrm{N}$ ratios of the three opioid peptides when a mixture of $10 \mathrm{ng} \mathrm{mL}^{-1}$ was loaded at different temperatures in the SPE microcartridge. In agreement with the preliminary experiments based on the internal thermostatization system, the $\mathrm{S} / \mathrm{N}$ of all peptides is increased as the temperature of the MTD during the loading/clean-up raises up to $60^{\circ} \mathrm{C}$.

Furthermore, the possibility to extend the studied ranges of MTD-temperatures with respect to the previous experiments demonstrate that $\mathrm{S} / \mathrm{N}$ do not increase indefinitely, but it became maximum when the temperature of the MTD is set at a certain intermediate temperature in the loading/clean-up step, which in this case was $60^{\circ} \mathrm{C}$. This temperature constitutes an optimum value and is valid for this specific combination of analytes and sorbent, but in other cases it should be experimentally determined.

The behavior observed in this case was in agreement with results of Purcell et al. [16,28-30] who reported similar behaviors of peptide retention in LC with temperature and explained them on the base of changes in peptide conformations. The fact that at the lowest temperature $\left(5^{\circ} \mathrm{C}\right)$, a very little increase of $\mathrm{S} / \mathrm{N}$ was observed in comparison with $25^{\circ} \mathrm{C}$, reinforced the hypothesis that complex mechanisms are involved in the retention and elution of the opioid peptides in SPE with C18 sorbents. Taking into account the two replicate $\mathrm{S} / \mathrm{N}$ values for each peptide at the different temperatures (Fig. 5), it can be noted that repeatability was excellent at any temperature. Consistent results were also obtained when the studies were repeated in different SPE-CE capillaries, which confirmed the reliability of the temperature control during SPE-CE, as well as the durability of microcartridges using high temperatures. Even after more than fifteen injections at these temperatures, no evidence of loss of retention capability or current instability was observed. This lifetime is very similar to that observed when microcartridges were used at regular temperatures $\left(25^{\circ} \mathrm{C}\right)$.
Fig. 6 shows the electropherograms obtained when a $10 \mathrm{ng}$ $\mathrm{mL}^{-1}$ standard solution of the three opioid peptides (A) and a human plasma sample spiked with $100 \mathrm{ng} \mathrm{mL}^{-1}$ of each of them (B) were loaded at $25^{\circ} \mathrm{C}$ and $60^{\circ} \mathrm{C}$. The increase of the loading temperature produced an evident improvement of the $\mathrm{S} / \mathrm{N}$ ratios and probably its LODs. Analyzing the standard solution the S/N resulted $150 \%, 37 \%$ and $35 \%$ greater for Dyn A, END and MET, respectively, while in the case of in the spiked plasma samples it resulted 42\%, 60\% and 39\% greater for Dyn A, END and MET, respectively.

These increments of $\mathrm{S} / \mathrm{N}$ can be traduced to improvements in the LODs which, on the base of the LODs reported in reference [8] for standard mixtures of the same three peptides in C18 sorbent at $25^{\circ} \mathrm{C}\left(10 \mathrm{ng} \mathrm{mL}^{-1}\right.$ in all cases), now using optimized temperatures on our thermostatting system can be estimated as $4 \mathrm{ng} \mathrm{mL}^{-1}$, $7 \mathrm{ng} \mathrm{mL}^{-1}$ and $7 \mathrm{ng} \mathrm{mL}^{-1}$ for Dyn A, END and MET, respectively. Differences observed in the electropherogram of standard solution respect to plasma samples (Fig. 6A vs Fig. 6B) with regard to the relative height of the different peptide peaks can be explained on the base of the recoveries: spiked plasma required a of the double step pretreatment which affected specially to Dyn A (23\%) [9].

\section{Conclusions}

The influence of temperature on C18-SPE-CE was studied using three opioid peptides as model compounds (Dyn A, END and MET). For this system it was demonstrated that temperature improves the $\mathrm{S} / \mathrm{N}$ ratios when the SPE microcartridge is at $60^{\circ} \mathrm{C}$ during the loading + clean-up step, and the temperature of the whole system is set at $25^{\circ} \mathrm{C}$ in the elution + separations step.

However, the capacity of the commercial instrument for handling temperature and use it as an optimization variable is quite limited. Therefore, a novel high-performance MTD was developed. It fits into the cassette of any commercial CE instrument and allows a local and independent thermostatization of the microcartridge in SPE-CE. An external circuit controls or rapidly switch the temperature of the water circulating through the MTD allowing to maintain the microcartridge temperature at a constant value or rapidly switching it between values as extreme as $5{ }^{\circ} \mathrm{C}$ and $90^{\circ} \mathrm{C}$. It was used to systematically study the effect of temperature on sample loading of three opioid peptides in C18-SPE-CE. Preconcentration factors showed a non-monotonous variation with temperature, obtaining the best results when sample is loaded at $60^{\circ} \mathrm{C}$. In the future, other sorbents and analytes could be tested, especially those whose retention will be dominated by large 
enthalpies, like adsorption mechanisms. Furthermore, the influence of temperature in other applications involving the on-line coupling of similar microcartridges (chemical or enzymatic reactors, filtration membranes, etc.) to $\mathrm{CE}$ could be easily explored.

\section{Acknowledgments}

This study was supported by CONICET (PIP-0777), ANPCyT (PICT2007-00316 and PICT-PRH2009-0038) in Argentina, and the Ministry of Education and Science (CTQ2011-27130) in Spain. The authors thank M. Barragan (La Plata, Argentina) by his collaboration in the construction of the MTD.

\section{References}

[1] G.A. Blanco, Y.H. Nai, E.F. Hilder, R.A. Shellie, G.W. Dicinoski, P.R. Haddad, et al. Identification of inorganic improvised explosive devices using sequential injection capillary electrophoresis and contactless conductivity detection, Anal. Chem. 83 (2011) 9068-9075.

[2] M.E. de Noo, R.a.E.M. Tollenaar, A. Ozalp, P.J.K. Kuppen, M.R. Bladergroen, P.H.C Eilers, et al., Reliability of human serum protein profiles generated with C8 magnetic beads assisted MALDI-TOF mass spectrometry, Anal. Chem. 77 (2005) 7232-7241.

[3] A.T. Aranas, A.M. Guidote, J.P. Quirino, Sweeping and new on-line sample preconcentration techniques in capillary electrophoresis, Anal. Bioanal. Chem. 394 (2009) 175-185.

[4] Z. Malá, P. Gebauer, P. Boček, Contemporary sample stacking in analytical electrophoresis, Electrophoresis 32 (2011) 116-126.

[5] R. Ramautar, G.W. Somsen, G.J. de Jong, Developments in coupled solid-phase extraction-capillary electrophoresis 2011-2013, Electrophoresis 35 (2014) 128-137.

[6] F. Benavente, M.C. Vescina, E. Hernández, V. Sanz-Nebot, J. Barbosa, N.a. Guzman, Lowering the concentration limits of detection by on-line solidphase extraction-capillary electrophoresis-electrospray mass spectrometry, J. Chromatogr. A 1140 (2007) 205-212.

[7] S. Medina-Casanellas, F. Benavente, J. Barbosa, V. Sanz-Nebot, Transient isotachophoresis in on-line solid phase extraction capillary electrophoresis time-of-flight-mass spectrometry for peptide analysis in human plasma, Electrophoresis 32 (2011) 1750-1759.

[8] F. Benavente, S. Medina-Casanellas, J. Barbosa, V. Sanz-Nebot, Investigation of commercial sorbents for the analysis of opioid peptides in human plasma by on-line SPE-CE, J. Sep. Sci. 33 (2010) 1294-1304.

[9] L. Pont, F. Benavente, J. Barbosa, V. Sanz-Nebot, An update for human blood plasma pretreatment for optimized recovery of low-molecularmass peptides prior to CE-MS and SPE-CE-MS, J. Sep. Sci. 36 (2013) 3896 3902.

[10] P. Puig, F. Borrull, M. Calull, C. Aguilar, Recent advances in coupling solid-phase extraction and capillary electrophoresis (SPE-CE), TrAC Trends Anal. Chem. 26 (2007) 664-678.

[11] N.A. Guzman, T.M. Phillips, Immunoaffinity CE for proteomics studies, Anal. Chem. 77 (2005) 60A-67A

[12] T. Teutenberg, H.-J. Goetze, J. Tuerk, J. Ploeger, T.K. Kiffmeyer, K.G. Schmidt, et al., Development and application of a specially designed heating system for temperature-programmed high-performance liquid chromatography using subcritical water as the mobile phase, J. Chromatogr. A 1114 (2006) 89-96.

[13] D. Cabooter, S. Heinisch, J.L. Rocca, D. Clicq, G. Desmet, Use of the kinetic plot method to analyze commercial high-temperature liquid chromatography systems. I: intrinsic performance comparison, J. Chromatogr. A 1143 (2007) $121-133$.

[14] L.G. Gagliardi, C.B. Castells, C. Ràfols, M. Rosés, E. Bosch, Modeling retention and selectivity as a function of $\mathrm{pH}$ and column temperature in liquid chromatography, Anal. Chem. 78 (2006) 5858-5867.

[15] P. a Babay, R.T. Gettar, J.F. Magallanes, E.T. Becquart, B. Thiele, D. a Batistoni, Column temperature as an active variable in the isocratic, normal-phase highperformance liquid chromatography separation of lipophilic metabolites of nonylphenol ethoxylates, J. Chromatogr. A 1157 (2007) 227-236.

[16] W. Purcell, M.I. Aguilar, M.T.W. Hearn, Conformational effects in reversedphase high-performance liquid chromatography of polypeptides II. The role of insulin A and B chains in the chromatographic behaviour of insulin, J. Chromatogr. A 711 (1995) 71-79.

[17] B.L. Karger, K.D. Snyder, C. Horváth, An Introduction to Separation Science, Wiley Inte, New York, 1973.

[18] Giddings, Dynamics of Chromatography, 1st ed., Marcel Dekker, 1965.

[19] N.A. Guzman, Electrophoresis apparatus having valve system. US patent 8007,725 B2, 2011.

[20] G.Y. Tang, C. Yang, J.C. Chai, H.Q. Gong, Joule heating effect on electroosmotic flow and mass species transport in a microcapillary, Int. J. Heat Mass Transf. 47 (2004) 215-227.

[21] R.S. Rush, a S. Cohen, B.L. Karger, Influence of column temperature on the electrophoretic behavior of myoglobin and alpha-lactalbumin in highperformance capillary electrophoresis, Anal. Chem. 63 (1991) 1346-1350.

[22] J.C. Reijenga, L.G. Gagliardi, E. Kenndler, Temperature dependence of acidity constants, a tool to affect separation selectivity in capillary electrophoresis, J. Chromatogr. A 1155 (2007) 142-145.

[23] V. Sanz-Nebot, F. Benavente, E. Hernández, J. Barbosa, Evaluation of the electrophoretic behaviour of opioid peptides separation by capillary electrophoresis-electrospray ionization mass spectrometry, Anal. Chim. Acta. 577 (2006) 68-76.

[24] D. Heiger, High-performance Capillary Electrophoresis, Agilent, 2000.

[25] P. Puig, F. Borrull, M. Calull, F. Benavente, V. Sanz-Nebot, J. Barbosa, et al., Improving the sensitivity of the determination of ceftiofur by capillary electrophoresis in environmental water samples: in-line solid phase extraction and sample stacking techniques, Anal. Chim. Acta. 587 (2007) 208-215.

[26] E. Hernández, F. Benavente, V. Sanz-Nebot, J. Barbosa, Analysis of opioid peptides by on-line SPE-CE-ESI-MS, Electrophoresis. 28 (2007) 3957-3965.

[27] H. Wätzig, M. Degenhardt, a Kunkel, Strategies for capillary electrophoresis: method development and validation for pharmaceutical and biological applications, Electrophoresis 19 (1998) 2695-2752.

[28] W. Purcell, M.I. Aguilar, M.T. Hearn, High-performance liquid chromatography of amino acids peptides, and proteins. 123. Dynamics of peptides in reversedphase high-performance liquid chromatography, Anal. Chem. 65 (1993) 3038-3047.

[29] W. Purcell, M. Aguilar, M.T. Hearn, Conformational effects in reversed-phase high-performance liquid chromatography of polypeptides I. Resolution of insulin variants, J. Chromatogr. A. 711 (1995) 61-70.

[30] A.W. Purcell, M.I. Aguilar, M.T.W. Hearn, High-performance liquid chromatography of amino acids, peptides and proteins CXV. Thermodynamic behaviour of peptides in reversed-phase chromatography, J. Chromatogr. A. 593 (1992) 103-117. 